\title{
Health risk assessment of occupational exposure to harmful chemical agents in a pesticide manufacturing plant
}

\author{
Laal F, MSc ${ }^{1}$, Hormozi, M, MSc ${ }^{1 *}$, Fallah Madvari R, MSc ${ }^{2}$, Noorizadeh N, MSc ${ }^{3}$, Firouzi \\ Chahak A, $\mathrm{MSc}^{4}$ \\ 1- Faculty Member, Health Promotion Research Center, Zahedan University of Medical Sciences, Zahedan, Iran. 2- MSc in \\ Occupational Health Engineering, Dept. of Occupational Health, School of Public Health, Shahid Sadoughi University of \\ Medical Sciences, Yazd, Iran. 3- MSc in Occupational Health Engineering, Student Research Committee, Dept. of \\ Occupational Health, Health School, Shahid Beheshti University of Medical Sciences, Tehran, Iran. 4- Faculty Member, \\ Dept. of Occupational Health, Faculty of Health, Gonabad University of Medical Sciences, Gonabad, Iran.
}

\begin{abstract}
Received: July 2017, Accepted: October 2017

Background: In most industries, employees are in contact with various chemical agents. The objective of this study was to assess the health risks posed by occupational exposure to harmful chemical agents in a pesticide manufacturing plant in Zahedan, Iran, in 2013.

Materials and Methods: This cross-sectional study was conducted in different units of a pesticide manufacturing plant. In order to evaluate the health risks associated with occupational exposure, a method provided by the Singapore Health Department was used. After identifying the pollutants, including benzene, toluene, ethylbenzene, and xylene (BTEX), $\mathrm{CO}, \mathrm{NO}, \mathrm{NO} 2$, and $\mathrm{H} 2 \mathrm{~S}$, the degree of risk, the degree of exposure of the employees to the chemical agents, and the level of health risk were calculated.

Results: The results showed that the highest hazard rate (HR) in all units was related to benzene and the lowest $\mathrm{HR}$ was related to $\mathrm{NO}$ and $\mathrm{H}_{2} \mathrm{~S}$. In the powder unit, the exposure rate (ER) and risk rate (RR) of $\mathrm{NO}_{2}$ were higher than other pollutants. Additionally, in different units, the RR of benzene was 2.23, which was the highest among the pollutants. Generally, the RR of all pollutants was very low (insignificant) and low.

Conclusions: By using information related to the risks of chemical agents and results of assessments of the health risks of exposure to chemical pollutants, different occupations can be ranked in terms of exposure to chemical risk factors. This ranking can be used to prioritize the allocation of resources for control measures and reduce exposure levels to acceptable levels.
\end{abstract}

Keywords: Risk Assessment, Occupational Exposure, Pesticide

\section{Introduction}

There are many chemical pollutants in enclosed industrial spaces and work environments, including gases, vapors, and particles. The hazards of these pollutants vary depending on the chemical substance, route of entry, duration of contact, and density (1-4). The diversity of chemicals as well as exposure to chemicals are rising annually, leading to an increase in related diseases and the deaths of many people in the industry (5).

Hence, identifying and evaluating industrial work environments is very important in this respect. For this purpose, assessing the health risks of chemicals is used as an appropriate tool for expressing the level of exposure of employees of industries to chemicals as well as anticipating control measures, training, monitoring, and health care for the protection of employees $(3,6)$. Assessing the risk of chemicals is a scientific assessment process that determines the level of risk and can help determine the appropriate risk management strategies and policies. Risk is a function of

\footnotetext{
* Corresponding author: Maryam Hormozi, Health Promotion Research Center, Zahedan University of Medical Sciences, Zahedan, Iran.

E-mail: hormozym@yahoo.com
} 
toxicity, risk potential, and exposure to chemicals (7).

Mckenzie et al., in a study in 2012, evaluated human health risk in the face of chemicals released from unconventional greenhouse gases, and highlighted the importance of applying risk management strategies to reduce individuals' exposure (8). Jahangiri et al. in 2011 (6), Golbabaei et al. in 2012 (5), and Wahhabi et al. in 2015 (9) conducted a risk assessment of chemicals using various methods in some industries. Their results indicated the applicability of risk assessment to corrective and control measures. Focusing on the pesticide industry, due to the release of hazardous chemicals in this industry, the present study highlighted the risk level of the pollutants in this industry. Pesticides that contain herbicides, insecticides, and fungicides are widely used to control pests and diseases caused by pests in the agricultural and public health sectors (10-12). In a review study conducted by Mehrpour et al. on pesticides and its consequences, it was found that the majority of pesticides including organ phosphorus compounds affect the male reproductive system through mechanisms including reduction of sperm density and motility (13). The production of various types of these products is increasing. Many people work in the manufacturing industries. Workers working in pesticide plants are at high risk of exposure to various chemicals and are susceptible to pesticides and other chemicals (14). Based on the experiences of many countries, the prevention of health risk caused by pesticides is technically feasible and risk assessment and appropriate management of pesticide use is an essential component of this prevention (15).

Therefore, in the present study, this method was used in a pesticide manufacturing plant to evaluate the risk level of exposure to chemicals in order to determine the control priorities and corrective actions to reduce risks to an acceptable level.

\section{Material and Methods}

This cross-sectional study was conducted in 2013 at an agricultural pest production plant. The census sampling method was used to select the study subjects. All workers who were working full-time in different units (powder, labs, insecticides, filling, and formulations units) and had contact with toxins and pesticides were included in the study (37 subjects). Those who met the inclusion criteria were included in this study and signed the informed consent form. Moreover, individuals who had at least one year of work experience were studied. In addition, all subjects were allowed to withdraw from the study at any stage.

The method used by the Singapore Health Department to assess the health risk of exposure to harmful chemical agents was adopted in this study, and its stages are described below $(3,16)$. Data used in this method include some information provided by organizations related to chemical hazards such as the International Agency for Research on Cancer (IARC), American Conference of Governmental Industrial Hygienists (ACGIH), and National Toxicology Program (NTP), which classify the chemicals in terms of health risks. The potential risks of chemicals can also be determined based on the classifications presented by these organizations. The variables used to determine the conditions of exposure include factors that depend on the inherent characteristics of the substance, such as the ratio of olfactory threshold to permissible exposure limit (OT/PEL), particle size of substances, and vapor pressure of chemicals, and some variables related to the conditions of use of chemicals, such as weekly consumption, duration of work with the chemical, and quality control methods. Chemicals used in this study included benzene, toluene, ethylbenzene, and xylene (BTEX), $\mathrm{CO}, \mathrm{NO}, \mathrm{NO}_{2}$, and $\mathrm{H}_{2} \mathrm{~S}$. In order to conduct this study, after determining the duties and tasks and identifying the pollutants and 
chemicals used at the site, the hazard rate of each of them was determined as explained below. Furthermore, the chemicals were identified based on previous sampling of ambient air according to standard methods which was done in 2012.

A) Hazard rate determination: The hazard rate (HR) or risk factor of various substances is determined according to the factors presented in table 1 .

Table 1: Determination of hazard rate based on toxic effects or carcinogenicity property

\begin{tabular}{|c|c|}
\hline Hazard rate & Hazard/effect classification description \\
\hline 1 & $\begin{array}{l}\text { - No adverse effects on health } \\
\text { Carcinogenicity A5 (ACGIH) } \\
\text { - It is not a toxic and harmful substance. }\end{array}$ \\
\hline 2 & $\begin{array}{l}\text { - Undesirable effects on the skin and mucosa (without high intensity) } \\
\text { Carcinogenicity A5 (ACGIH) } \\
\text { - Creating sensitivity and stimulating the skin }\end{array}$ \\
\hline 3 & $\begin{array}{l}\text { - Carcinogenicity and mutagenesis in humans or animals (sufficient information has } \\
\text { not yet been provided) } \\
\text { Carcinogenicity A3 (ACGIH) } \\
\text { - Group 2B (IARC) } \\
\text { - Corrosive substance }(5>\mathrm{PH}>3 \text { or } 11>\mathrm{PH}>9 \text { ) } \\
\text {-Respiratory stimulation as component of harmful substances }\end{array}$ \\
\hline 4 & $\begin{array}{l}\text { - Possibility of carcinogenicity, mutagenesis, and genetic disorders (based on studies } \\
\text { on laboratory organisms) } \\
\text { - Carcinogenicity A2 (ACGIH) } \\
\text { - Group A2 (IARC) } \\
\text { - Group B (NTP) } \\
\text { - Very corrosive substance }(2>\mathrm{PH}>0 \text { or } 14>\mathrm{PH}>5.11) \\
\text { - Toxic substance }\end{array}$ \\
\hline 5 & $\begin{array}{l}\text { - Carcinogenic, mutagenesis, and cause of genetic disorders in infants } \\
\text { Carcinogenicity A1 (ACGIH) } \\
\text { Group } 1 \text { (IARC) } \\
\text { - Group A (NTP) } \\
\text { - Very toxic substance }\end{array}$ \\
\hline
\end{tabular}

ACGIH: American Conference of Governmental Industrial Hygienists; IARC: International Agency for Research on Cancer; NTP: National Toxicology Program

\section{B) Determination of exposure rate:} Exposure rate (ER) can be obtained by determining the actual exposure level (when air monitoring results are available) or by determining the exposure index (EI) when the air monitoring results are not available. The second method was used in this study to determine ER. For this purpose, first, EI was calculated. EI, as previously indicated, was determined based on the physicochemical properties of harmful chemicals, vapor pressure, OT/PEL, toxicology information, the level, frequency, duration, and routes of exposure, hazard control measures, and other related information (17). Then, ER was determined based on the following formula:
$E R=\left[(\mathrm{EI})_{1} \times(\mathrm{EI})_{2} \times \ldots(\mathrm{EI})_{\mathrm{n}}\right]^{1 / \mathrm{n}}$

Where $\mathrm{n}$ is the number of exposure factors used.

EI has been ranked from 1 to 5 in numerical scales in terms of severity of exposure, meaning that the number 1 represents low exposure severity and the number 5 represents high exposures severity (17).

C) Determination of risk rate: After determining HR and ER, the risk rate (RR) is obtained according to the following equation:

$R R=\sqrt{H R \times E R}$

The reason for taking the square root of the resulting is to get a number in the range of 1 to 5. The risk of each duty and its ranking is determined in table 2 . 
Table 2: Determining the risk rate

\begin{tabular}{ccc}
\hline Ranking & Level of risk & Risk rate \\
\hline Very low-negligible & 1 & $0-1.7$ \\
\hline Low & 2 & $1.7-2.8$ \\
\hline Average & 3 & $2.8-3.5$ \\
\hline High & 4 & $3.5-4.5$ \\
\hline Very high & 5 & $4.5-5$ \\
\hline
\end{tabular}

This rating will help us take corrective measures to reduce the risk in the pesticide industry. If the assessment shows that there is a significantly high risk for a task or duty, appropriate corrective actions should be considered for that task.

Table 3: Determination of the chemical risk rating of different chemicals separately in different units of a pesticide manufacturing plant

\begin{tabular}{|c|c|c|c|c|c|}
\hline Unit & Pollutant name & HR & $\mathbf{E R}$ & $\mathbf{R R}$ & Quality Risk Coefficient \\
\hline \multirow{8}{*}{ Powder unit } & Benzene & 5 & 1 & 2.23 & Low \\
\hline & Toluene & 3 & 1 & 1.7 & Very low-negligible \\
\hline & Xylene & 2 & 1 & 1.4 & Very low-negligible \\
\hline & Ethylbenzene & 3 & 1 & 1.7 & Very low-negligible \\
\hline & $\mathrm{Co}$ & 4 & 1 & 2 & Low \\
\hline & No & 1 & 1 & 1 & Very low-negligible \\
\hline & $\mathrm{No}_{2}$ & 2 & 2 & 2 & Low \\
\hline & $\mathrm{H}_{2} \mathrm{~S}$ & 1 & 1 & 1 & Very low-negligible \\
\hline \multirow{8}{*}{$\begin{array}{c}\text { Laboratory } \\
\text { unit }\end{array}$} & Benzene & 5 & 1 & 2.23 & Low \\
\hline & Toluene & 3 & 1 & 1.7 & Very low-negligible \\
\hline & Xylene & 2 & 1 & 1.4 & Very low-negligible \\
\hline & Ethylbenzene & 3 & 1 & 1.7 & Very low-negligible \\
\hline & $\mathrm{Co}$ & 4 & 1 & 2 & Low \\
\hline & No & 1 & 1 & 1 & Very low-negligible \\
\hline & $\mathrm{No}_{2}$ & 2 & 1 & 1.4 & Very low-negligible \\
\hline & $\mathrm{H}_{2} \mathrm{~S}$ & 1 & 1 & 1 & Very low-negligible \\
\hline \multirow{8}{*}{$\begin{array}{l}\text { Insecticide } \\
\text { unit }\end{array}$} & Benzene & 5 & 1 & 2.23 & Low \\
\hline & Toluene & 3 & 1 & 1.7 & Very low-negligible \\
\hline & Xylene & 2 & 1 & 1.4 & Very low-negligible \\
\hline & Ethylbenzene & 3 & 1 & 1.7 & Very low-negligible \\
\hline & $\mathrm{Co}$ & 4 & 1 & 2 & Low \\
\hline & No & 1 & 1 & 1 & Very low-negligible \\
\hline & $\mathrm{No}_{2}$ & 2 & 1 & 1.4 & Very low-negligible \\
\hline & $\mathrm{H}_{2} \mathrm{~S}$ & 1 & 1 & 1 & Very low-negligible \\
\hline \multirow{8}{*}{ Filling unit } & Benzene & 5 & 1 & 2.23 & Low \\
\hline & Toluene & 3 & 1 & 1.7 & Very low-negligible \\
\hline & Xylene & 2 & 1 & 1.4 & Very low-negligible \\
\hline & Ethylbenzene & 3 & 1 & 1.73 & Low \\
\hline & $\mathrm{Co}$ & 4 & 1 & 2 & Low \\
\hline & No & 1 & 1 & 1 & Very low-negligible \\
\hline & $\mathrm{NO}_{2}$ & 2 & 2 & 2 & Low \\
\hline & $\mathrm{H}_{2} \mathrm{~S}$ & 1 & 1 & 1 & Very low-negligible \\
\hline \multirow{8}{*}{$\begin{array}{c}\text { Formulation } \\
\text { unit }\end{array}$} & Benzene & 5 & 1 & 2.23 & Very low-negligible \\
\hline & Toluene & 3 & 1 & 1.7 & Very low-negligible \\
\hline & Xylene & 2 & 1 & 1.4 & Very low-negligible \\
\hline & Ethylbenzene & 3 & 2 & 2.4 & Low \\
\hline & $\mathrm{Co}$ & 4 & 1 & 2 & Low \\
\hline & No & 1 & 1 & 1 & Very low-negligible \\
\hline & $\mathrm{No}_{2}$ & 2 & 2 & 2 & Low \\
\hline & $\mathrm{H}_{2} \mathrm{~S}$ & 1 & 2 & 1.4 & Very low-negligible \\
\hline
\end{tabular}

HR: Hazard rate; ER: Exposure rate; RR: Risk rate

\section{Results}

In the studied subjects, a total of 37 individuals were present in different units, of which 15 were woman. Individuals had different tasks in these units. For example, the main tasks in the laboratory unit were 
pesticides sampling, materials inspection (raw materials, labels, bottles, doors, and etc.), and pesticides quality control. In the liquid and powder insecticide production unit, the mixing of raw materials, filtering, filling bottles, sealing, and bottling were the most important tasks. Table 3 shows the RR of gases and chemical vapors in various units of the studied plant. According to the results in all units, the HR of benzene was higher than the other studied pollutants and the HRs of $\mathrm{NO}$ and $\mathrm{H}_{2} \mathrm{~S}$ were lower than the other studied pollutants. In the powder unit, the ER (2) and the RR of $\mathrm{NO}_{2}$ (2.23) were higher than the other pollutants. Generally, in all units, the RR of benzene was 2.23 , which was the highest among pollutants in the work environment. The second highest $\mathrm{RR}$ among all units was related to toluene. The lowest RR in different units is also given in table 3, which usually included $\mathrm{H}_{2} \mathrm{~S}$ and NO. In addition, according to table 3 and based on the classification of table 2, RR was in the range of 0-1.7 (very low, negligible) and 1.72.8 (low) in almost all units and for all chemicals. The highest risk rate was also related to benzene (low: 2.23).

\section{Discussion}

The employees studied in this research were exposed to the 8 chemical pollutants of BTEXs, $\mathrm{CO}, \mathrm{NO}, \mathrm{NO}_{2}$, and $\mathrm{H}_{2} \mathrm{~S}$ during their work. BTEX are among the most important volatile compounds with similar physical and chemical properties. In the present study, the $\mathrm{RR}$ of all pollutants in all units was very low and low. It should be noted that the permitted amount of benzene in Iran is $0.5 \mathrm{ppm}$. The highest RR was related to benzene because it has a higher risk factor, and as it is not possible to remove it from the units, it is necessary to take control measures to reduce the risk of exposure to it, although it was reported at a low and very low level. Toluene was ranked second in this regard. In the case of toluene, xylene, ethylbenzene, $\mathrm{CO}$, NO, $\mathrm{NO}_{2}$, and $\mathrm{H}_{2} \mathrm{~S}$, the priority in terms of control action is to reduce the amount of exposure by modifying the working method and the ventilation system and using appropriate protective equipment. In a study conducted by Mousavi-Fard et al. to assess the risk of toluene diisocyanate (TDI) and methylene diisocyanate (MDI) in car paint shops in Alborz Province, Iran, the highest risk factor and concentration were related to TDI (18). Contrary to the findings of the present study, the results of the study by Zare Jedi et al. showed that occupational exposure to benzene was at a dangerously high level in refueling stations (19). Furthermore, they concluded that the risk of cancer is potentially high among individuals working at refueling stations due to inhalation exposure (19). Wang et al. studied the status of pollution and the health risks of BTEX in air, soil, dust, and groundwater in the area surrounding a pesticide manufacturing plant in China (20). They found that the concentration of BTEX in the air and the soil were below related standards of China, however integrated risk management was proposed to protect occupational health (20), which was similar to the results of this study. Moreover, in the study by Beheshti et al., with aim of risk assessment of health exposure to hazardous chemical agents in a petrochemical plant, among the different materials which people are exposed to, benzene and xylene had the highest risks and were used in various occupations (21). In the study by Golbabaie, among about 40 chemical substances, benzene was introduced as the most hazardous chemical in the petrochemical industry (5). In this study, as previously mentioned, the highest RRs were related to benzene and toluene, respectively. Several studies, such as those by Harati (22) and Ding and Bao (23), have also pointed to the adverse effects of BTEX. Harati et al. showed that exposure to benzene can increase the risk of cancer and risk assessment and cancer risk analysis can provide valuable information on the control procedures in the petrochemical industry (22). In another study conducted in China, Ding and Bao showed that exposure to pesticides is likely to be related to the physical health of 
children, and improving epidemiological programs and methods for assessing and integrating this information with toxicological data will lead to better assessments (23). In the pesticide industry, due to the active presence of women and the adverse effects of pesticides on newborns (24), women should try to avoid exposure to pesticides and high risk units during pregnancy and lactation, and they should be employed in low risk units. According to the results of the study conducted by Mamani et al. in 2015, occupational exposure to pesticides is related with an increased risk of respiratory symptoms and chronic bronchitis, but its causal relationship is still under debate (25). Therefore, control measures should always be taken into consideration. Although the amount of pollution was lower than the permitted level in this plant, it is still necessary to take measures to reach an ideal industry. This permitted level is proposed for healthy individuals, and some individuals may be exposed to pollutants in the work environment more than others due to factors such as age and individual sensitivity.

\section{Conclusion}

By using information about the hazards of chemical agents and results of the assessment of the health risks of exposure to chemical pollutants, different occupations can be ranked in terms of exposure to the risk factors. This ranking can be used to prioritize resources for taking control measures and reduce the level of risk of exposure to acceptable levels. Taking exposure control measures including technical control, engineering, and management measures, continuous monitoring of the work environment, and risk reassessment after the interventions necessary to minimize the pollutants is suggested.

\section{Acknowledgment}

This article is a result of a research project approved by Zahedan University of Medical Sciences. Thereby, we appreciated the deputy of research and technology of the university for funding this study.

Conflict of interest: None declared

\section{References}

1. McDermott HJ. Air monitoring for toxic exposures. $2^{\text {nd }}$ ed. Hoboken, New Jersey, United States: John Wiley \& Sons, Inc; 2004.

2. Roberts SM, James RC, Williams PL. Principles of toxicology: environmental and industrial applications. $3^{\text {rd }}$ ed. Hoboken, New Jersey, United States: John Wiley \& Sons, Inc; 2015.

3. Jahangiri M, Motovagheh M. Health risk assessment of harmful chemicals: case study in a petrochemical industry. Iran Occupational Health 2011; 7(4):18-24.

4. Guo H, Kwok NH, Cheng HR, Lee SC, Hung WT, Li YS. Formaldehyde and volatile organic compounds in Hong Kong homes: concentrations and impact factors. Indoor Air 2009; 19(3):206-17.

5. Golbabaie F, Eskandari D, Rezazade Azari M, Jahangiri M, Rahimi M, Shahtaheri J. Health risk assessment of chemical pollutants in a petrochemical complex. Iran Occupational Health 2012; 9(3):11-21.

6. Karimi A, Jamshidi Slukloei HR, Eslamizad S. Designing SQCRA as a software to semiquantitative chemical risk assessment in workplace. Journal of Occupational Hygiene Engineering 2014; 1(2):47-56.

7. Pease CK, Gentry RP. Systematic review in chemical risk assessment - A chemical industry perspective. Environ Int 2016; 92-93:574-7.

8. McKenzie LM, Witter RZ, Newman LS, Adgate JL. Human health risk assessment of air emissions from development of unconventional natural gas resources. Sci Total Environ 2012; 424:79-87.

9. Vahabi M, Mazinani M, Kdakaram S, Rezazadeh M, Khiri H, Mosavi AA, et al. Irritation risk assessment of occupational exposure to formaldehyde from Melamine dinnerware workshops in Tehran. Iran Occupational Health 2016; 13(2):50-7.

10. García-García $C R$, Parrón $T$, Requena $M$, Alarcón R, Tsatsakis AM, Hernández AF. Occupational pesticide exposure and adverse health effects at the clinical, hematological and biochemical level. Life Sci 2016; 145:274-83.

11. Damalas CA, Eleftherohorinos IG. Pesticide exposure, safety issues, and risk assessment indicators. Int $\mathrm{J}$ Environ Res Public Health 2011; 8(5):1402-19. 
12. Kim KH, Kabir E, Jahan SA. Exposure to pesticides and the associated human health effects. Sci Total Environ 2017; 575:525-35.

13. Mehrpour O, Karrari P, Zamani N, Tsatsakis AM, Abdollahi M. Occupational exposure to pesticides and consequences on male semen and fertility: a review. Toxicol Lett 2014; 230(2):146-56.

14. Bian Q, Xu LC, Wang SL, Xia YK, Tan LF, Chen JF, et al. Study on the relation between occupational fenvalerate exposure and spermatozoa DNA damage of pesticide factory workers. Occup Environ Med 2004; 61(12):999-1005.

15. Maroni M, Fanetti AC, Metruccio F. Risk assessment and management of occupational exposure to pesticides in agriculture. Med Lav 2006; 97(2):430-7.

16. Ministry of Manpower, Occupational Safety and Health Division Singapore. A semiquantitative method to assess occupational exposure to harmful chemicals. Singapore: Ministry of Manpower. Available from: https://www.wshc.sg/files/wshc/upload/cms/fil e/2014/A\%20Semiquantitative\%20Method\%2 0to\%20Assess\%20Occupational\%20Exposure $\% 20$ to $\% 20$ Harmful\%20Che.pdf

17. Huang D, Zhang J, Liu M. Application of a health risk classification method to assessing occupational hazard in China. Paper presented at: The $3^{\text {rd }}$ International Conference on Bioinformatics and Biomedical Engineering; 2009 June 11-13; Beijing, China.

18. Moosavifard SA, Ardestani M, Zarei F, Asgarianzadeh M. Semi-quantitative risk assessment of TDI and MDI in car paint shops in Alborz province, Iran. Journal of Mazandaran University of Medical Sciences 2016; 25(132):82-90.
19. Zare Jeddi M, Yunesian M, Ahmadkhaniha R, Kashani H, Rastkari N. Semi-quantitative and quantitative health risk assessment of gas station workers exposure to benzene. Iranian Journal of Health and Environment 2015; 8(3):391-400.

20. Wang T, Bo P, Bing T, Zhaoyun Z, Liyu D, Yonglong L. Benzene homologues in environmental matrixes from a pesticide chemical region in China: occurrence, health risk and management. Ecotoxicol Environ Saf 2014; 104:357-64.

21. Beheshti MH, Firoozi Chahak A, Alinaghi Langari AA, Rostami S. Semi-quantitative risk assessment of health exposure to hazardous chemical agents in a petrochemical plant. Journal of Occupational Health and Epidemiology 2015; 4(1):1-8.

22. Harati A, Shahtaheri SJ, Yousefi HA, Askari A, Abdolmohamadi N, Sayyahi Z, et al. Risk assessment of chemical pollutants in a petrochemical company. Peper presented at: The $6^{\text {th }}$ Iranian Conference Energy Management and Environment; 2016 Dec 22; Tehran, Iran.

23. Ding G, Bao Y. Revisiting pesticide exposure and children's health: focus on China. Sci Total Environ 2014; 472:289-95.

24. Monteagudo C, Mariscal-Arcas M, HerasGonzalez L, Ibanez-Peinado D, Rivas A, OleaSerrano F. Effects of maternal diet and environmental exposure to organochlorine pesticides on newborn weight in Southern Spain. Chemosphere 2016; 156:135-42.

25. Mamane A, Baldi I, Tessier JF, Raherison C, Bouvier G. Occupational exposure to pesticides and respiratory health. Eur Respir Rev 2015; 24(136):306-19. 